OPEN ACCESS

Edited by:

Yves Jacquot,

Université Paris Descartes, France

Reviewed by:

Richard T. Premont,

Harrington Discovery Institute,

United States

Alain Couvineau,

Institut National de la Santé et de la

Recherche Médicale

(INSERM), France

*Correspondence:

Damian Jacenik

damian.jacenik@biol.uni.lodz.pl

Wanda M. Krajewska

wanda.krajewska@biol.uni.lodz.pl

Specialty section:

This article was submitted to

Molecular and Structural

Endocrinology,

a section of the journal

Frontiers in Endocrinology

Received: 26 March 2020

Accepted: 15 May 2020

Published: 12 June 2020

Citation:

Jacenik D and Krajewska WM (2020)

Significance of $G$ Protein-Coupled Estrogen Receptor in the

Pathophysiology of Irritable Bowel Syndrome, Inflammatory Bowel Diseases and Colorectal Cancer.

Front. Endocrinol. 11:390

doi: 10.3389/fendo.2020.00390

\section{Significance of G Protein-Coupled Estrogen Receptor in the Pathophysiology of Irritable Bowel Syndrome, Inflammatory Bowel Diseases and Colorectal Cancer}

\author{
Damian Jacenik* and Wanda M. Krajewska* \\ Department of Cytobiochemistry, Faculty of Biology and Environmental Protection, University of Lodz, Lodz, Poland
}

The regulatory role of estrogens and nuclear estrogen receptors, i. e., estrogen receptor $\alpha$ and $\beta$ has been reported in gastrointestinal diseases. However, the contribution of $G$ protein-coupled estrogen receptor, the membrane-bound estrogen receptor, is still poorly understood. Unlike nuclear estrogen receptors, which are responsible for the genomic activity of estrogens, the G protein-coupled estrogen receptor affects the "rapid" non-genomic activity of estrogens, leading to modulation of many signaling pathways and ultimately changing gene expression. Recently, the crucial role of G protein-coupled estrogen receptor in intestinal pathogenesis has been documented. It has been shown that the $\mathrm{G}$ protein-coupled estrogen receptor can modulate the progression of irritable bowel syndrome, inflammatory bowel diseases such as Crohn's disease and ulcerative colitis as well as colorectal cancer. The G protein-coupled estrogen receptor appears to be a potent factor regulating abdominal sensitivity and pain, intestinal peristalsis, colitis development, proliferation and migration potential of colorectal cancer cells and seems to be a useful target in gastrointestinal diseases. In this review, we present the current state of knowledge about the contribution of the G protein-coupled estrogen receptor to irritable bowel syndrome, inflammatory bowel diseases and colorectal cancer.

\footnotetext{
Keywords: G protein-coupled estrogen receptor, irritable bowel syndrome, inflammatory bowel diseases, Crohn's disease, ulcerative colitis, colorectal cancer
}

\section{INTRODUCTION}

The G protein-coupled estrogen receptor (GPER, previously known as GPR30) is a seventransmembrane receptor discovered, among others, in breast cancer tissue and estrogen receptorpositive MCF-7 cell line (1-7). In addition to acting via nuclear estrogen receptors (ERs), i.e., ER $\alpha$ and ER $\beta$, estrogens have been reported to induce ligand-dependent signaling by the membranebound estrogen receptor named GPER. In contrast to nuclear ERs, which predominantly regulate expression of target genes through direct interaction with estrogen response element or indirectly through transcription factors, GPER is responsible for "rapid" non-genomic activity of estrogens, leading to modulation of many signaling pathways and ultimately gene expression. Studies of the mechanisms underlying the effects of GPER under physiological and pathological conditions 
have shown that activation of GPER leads to stimulation of signaling pathways dependent on both $G \alpha_{s}$ and $G \beta \gamma$ proteins. Epidermal growth factor receptor (EGFR), mitogenactivated protein kinases (MAPKs), phosphatidylinositol 3kinase (PI3K), phospholipase C (PLC) and adenylyl cyclase (AC) are the main GPER-dependent pathways regulated by the action of $G$ proteins (8-12). It was also found that GPER is capable to affect nuclear factor- $\kappa \mathrm{B}(\mathrm{NF}-\kappa \mathrm{B})$ and Notch as well as Hippo signaling, where the membrane-bound estrogen receptor regulates phosphorylation of crucial proteins through $\mathrm{G} \alpha_{\mathrm{q}-11}$ action, enhancing the proliferation and migration potential of breast cancer cells $(11,13,14)$. GPER action appears unrelated to $G$ protein-independent signals such as $\beta$ arrestin recruitment $(15,16)$. Beyond $17 \beta$-estradiol, which is a natural agonist of GPER, various ligands have an affinity for this estrogen receptor (Figure 1). Among them there are therapeutic agents that belong to the classes of selective nuclear ER modulators (e.g., tamoxifen), selective nuclear ER downregulators (e.g., fulvestrant), and xenoestrogens (e.g., atrazine, bisphenol A, genistein and quarcetin) as well as synthetic GPER selective agonist (i.e., G-1) and antagonists (i.e., G15 and G36) (17). All synthetic GPER selective ligands are based on the tetrahydro-3H-cyclopenta[c] quinoline scaffold, but the GPER antagonist G15 is characterized by the absence of ethanone moiety compared to the GPER agonist G-1, while the second GPER antagonist, i.e., G36, has an isopropyl moiety in the place of the ethanone moiety at position C8.

GPER expression is not restricted to estrogen responsive tissues. GPER is widely expressed in human tissues, including breast, ovaries, uterus, placenta, testis, prostate, bone marrow, thymus, bones, smooth and skeletal muscles, brain, blood vessels, heart, lung, liver and intestine (18). Considerable evidence suggests that GPER is essential in cardiovascular diseases, obesity, diabetes, immune disorders and infectious diseases as well as in neoplastic transformation and tumor progression $(17,19,20)$. In this review, we summarize the evidence for GPER expression and function in the pathophysiology of intestinal diseases, i.e., irritable bowel syndrome, inflammatory bowel diseases and colorectal cancer.

\section{IRRITABLE BOWEL SYNDROME}

Irritable bowel syndrome (IBS) is a common, functional gastrointestinal disorder that is manifested by abdominal pain and bowel habit disturbance. From a clinical point of view, IBS is divided into subtypes related to changes in gastrointestinal motility, i.e., diarrhea-predominant IBS (IBS-D), constipationpredominant IBS (IBS-C) and IBS with altered bowel habits (IBSA or IBS-M). The pathophysiology of IBS is still elusive, but several factors such as microbiota, environmental and genetic variations, seem to be responsible for the development of IBS.

The first evidence suggesting the importance of GPER in IBS was revealed by Qin et al. (21) who evaluated the expression of estrogen receptor genes in the intestine of IBS patients. Higher expression of GPER at mRNA level in the intestine of IBS-D patients in relation to IBS-C patients and healthy subjects was documented. Jacenik et al. (22) also observed overexpression of GPER at the level of mRNA in colonic tissue, but in both IBS$\mathrm{C}$ and IBS-D patients. However, after taking into account the sex and age of the patients, statistically significant overexpression of GPER at mRNA level was observed only in men with IBS-D, suggesting a gander-specific role of estrogen signaling through this estrogen receptor in the progression of functional bowel diseases.

There are several hypotheses regarding the mechanisms by which GPER may be engaged in the progression of IBS, one of which is related with mast cell regulation. Mast cells are one of the main cell types involved in the activation of immune response in the gastrointestinal tract. Stimulated mast cells degranulate and release a wide spectrum of mediators such as amines, proteoglycans, proteases and lysosomal enzymes as well as cytokines, which leads to modulation of permeability and regulation of smooth muscle contraction (23). In IBS, alteration of mast cells number or density in the intestine was documented in several independent studies and seems to be associated with IBS pathogenesis (24-26). Although the results of Sundin et al. (27) indicate that there is no change in the infiltration and localization of mast cells in the colonic mucosa of IBS patients compared to healthy individuals, they report evidence indicating a relationship between abdominal sensitivity and mast cell number. GPER seems to be expressed in the tryptase ${ }^{+}$mast cells and the expression of GPER in the cytoplasm of mast cells and $\mathrm{GPER}^{+}$cells was found to be significantly higher in the colonic mucosa of IBS-D patients compared to IBS-C patients and healthy subjects. It should be noted that Qin et al. (21) found a positive correlation between the number of GPER ${ }^{+}$cells and the severity of abdominal pain and not the duration of symptoms in the IBS-D patients. The importance of GPER activity modulation on abdominal pain was confirmed in a mouse model. Zielinska et al. (28) found that treatment with GPER agonists, i.e., 17 $\beta$ estradiol or G-1, is associated with lower pain-induced behaviors in mice treated with mustard oil. In contrast, GPER selective antagonist G15 reduces the positive effect of GPER agonists on pain-induced behaviors.

In vivo studies in which $\mathrm{Xu}$ et al. (29) used control, stressed, and ovariectomized (OVX) rats revealed that estrogen receptor ligands acting through GPER are able to regulate visceral hypersensitivity, mast cell degranulation and mast cell tryptase expression as well as histamine levels in rat intestine. It was estimated that rats subjected to wrap partial restraint stress were characterized by increased visceromotor response. In the intestine of stressed rats a higher number of mast cells and up-regulated level of histamine were found. Both effects were reduced when OVX rats were used compared to control rats. Xu et al. (29) observed that the administration of $17 \beta$-estradiol led to an increase of visceromotor response, but pre-treatment with the GPER selective antagonist G15 counteracted the enhancing effects in OVX rats. Consistent with this, OVX rats treated with GPER selective agonist G-1 manifested dose-dependent upregulated visceromotor response levels. It should be noted that in addition to modulating visceral motor response, GPER ligands also affect the expression level of tryptase in mast cells and histamine in the rat intestines, indicating the important role of 


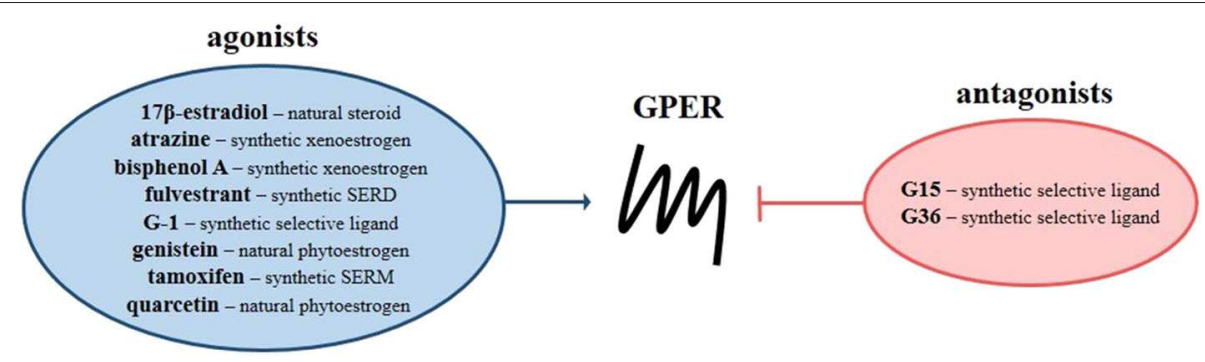

FIGURE 1 | G protein-coupled estrogen receptor ligands. Scheme presents natural and synthetic agonists (blue circle) and antagonists (red circle) of GPER. SERD, selective nuclear estrogen receptor down-regulators; SERM, selective nuclear estrogen receptor modulators.

GPER and mast cells in colon hypersensitivity in the female IBS rat model (29).

Mast cells appear not to be the only cell type involved IBS development. Enteric neurons and enteric glial cells play an essential role in the regulation of gastrointestinal motility, and motility impairment is the main hallmark of functional gastrointestinal diseases, including IBS. It has to be noted that changes in gastrointestinal motility are primarily driven by alteration of enteric nervous system, i.e., complex network of enteric neurons and glia which regulate for instance fluid exchange across the mucosa, blood flow in the intestine and gastrointestinal motility $(30,31)$. GPER has been shown to be expressed in the neuronal population of cells in the human and mouse intestines $(29,32,33)$. Liu et al. (33) by immunofluorescent staining documented that GPER is present in the cytoplasm of enteric neurons and glial cells of the stomach, duodenum, jejunum, ileum and colon of male and female mice.

Two independent studies indicate that modulation of GPER activity affects colonic motility involving both neuronal cells and circular muscle strip contraction $(28,32)$. It was found that GPER inhibition with the GPER selective antagonist G15 decreases colonic transit time in the proestrus and estrus phases but not diestrus stage compared to untreated phase-matched female mice. It has been proven that $17 \beta$-estradiol administration prolonged the colonic transit time while G15 treatment reduced the effect of exogenous estrogen on colonic transit time in OVX mice. Ex vivo analysis using colonic circular muscle strips confirmed that GPER activation with the GPER selective agonist G-1 reduced the contractile response of the muscle strips to carbachol and this phenomenon was abolished by tetrodotoxin, suggesting that GPER may act through a neurogenic mechanism. In fact, it has been documented that GPER activation stimulated the release of nitric oxide in myenteric neurons, which was decreased by the nitric oxide synthase inhibitor (32). In vivo experiments using colonic bead expulsion test and mouse model of hypermotility carried out by Li et al. (32) and Zielinska et al. (28) have documented that GPER activation prolongs colonic transit time and is associated with lower number of fecal pellets.

Potential mechanisms by which GPER can modulate progression of irritable bowel syndrome are summarized in Figure 2.

\section{INFLAMMATORY BOWEL DISEASES}

Crohn's disease (CD) and ulcerative colitis (UC) are the major types of inflammatory bowel disease (IBDs) that manifest themselves as chronic intestine inflammation. The most evidence emphasizing estrogen significance in IBDs comes from clinical observations that take into account hormone fluctuations in premenopausal and post-menopausal women in the prevalence and symptoms of IBDs (34-36). On the other hand, many reports indicate that estrogen receptors regulate the immune response affecting not only intestinal cells, but also immune cells (37-41). However, the importance of $\mathrm{G}$ protein-coupled estrogen receptor in IBDs is still poorly understood, but available data indicate that GPER may be involved in the pathways responsible for progression of IBDs.

It was documented that patients with $\mathrm{CD}$ and UC are characterized by a lack of changes, both in the level of circulating $17 \beta$-estradiol and enzymes involved in estrogen metabolism in relation to reference values and control group. Nevertheless, alterations in estrogen receptor expression, including GPER were found in the intestine of patients with IBDs (42-44). Significantly higher levels of GPER in the intestine have been demonstrated in both CD and UC patients compared to healthy controls. Higher expression of GPER at the mRNA level was also observed in an independent cohort using dataset provided by Gene Expression Omnibus. Nevertheless, when sex and age of women were taken into consideration, higher expression of GPER at the protein level was found in the intestine of men with both types of IBDs in relation to sex-matched controls. In the case of women, upregulation of GPER expression in the intestine of women with UC under the age of 50 compared to sex and age-matched controls was noted (43). Interesting evidence was also provided by Włodarczyk et al. (42) who documented differences in GPER expression in non-inflamed and inflamed intestine obtained from patients with $\mathrm{CD}$, but not in patients with UC. Alterations in GPER expression in IBDs suggest that GPER may be involved in the immune response in the progression of colitis in patients with CD and UC.

The functional significance of GPER in CD was provided by in vivo studies using trinitrobenzene sulfonic acid (TNBS)induced $\mathrm{CD}$ model in mice $(44,45)$. It was demonstrated that modulation of GPER activity using estrogen receptor agonists and antagonists affects the development of colitis. 


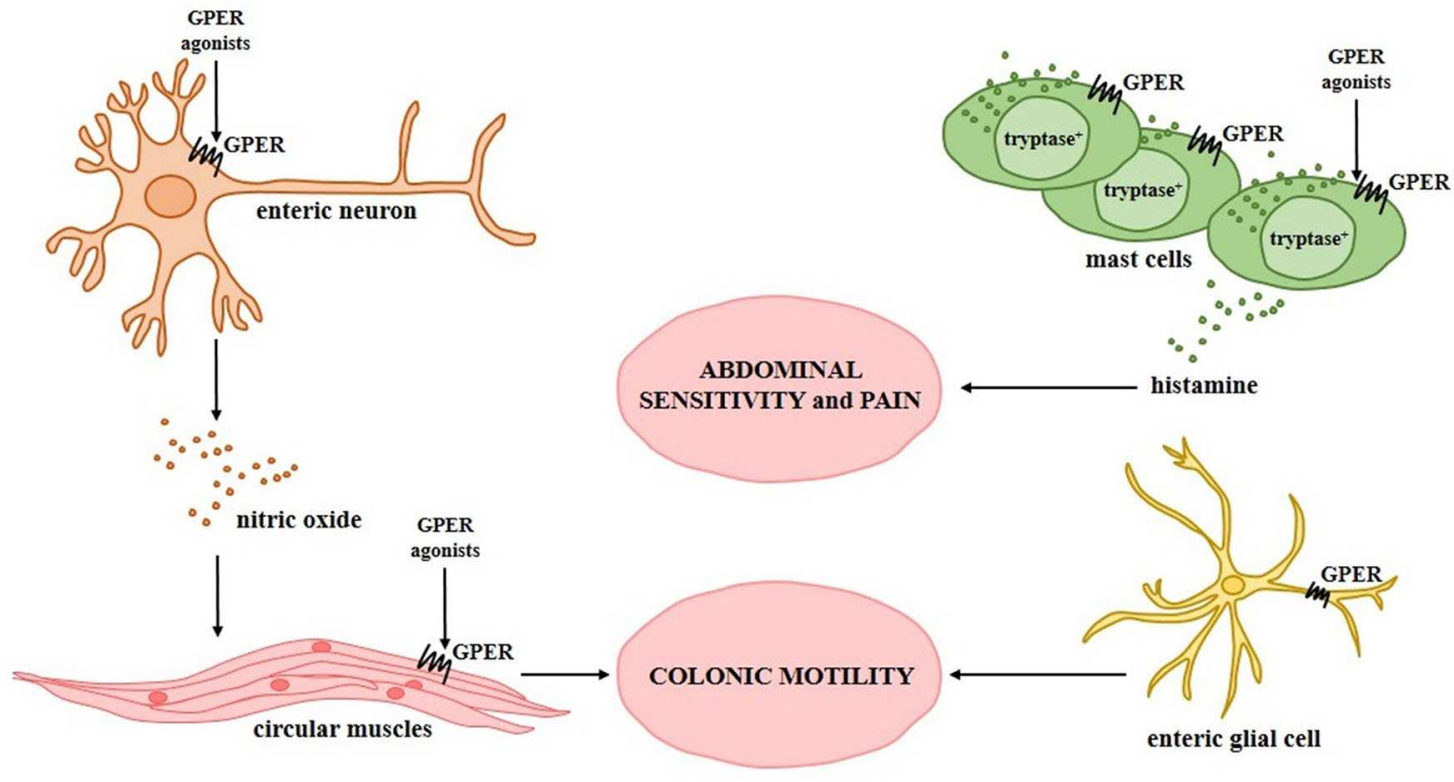

FIGURE 2 | Relationship between G protein-coupled estrogen receptor and irritable bowel syndrome. Experimentally confirmed GPER activity in specific types of intestinal cells during the progression of irritable bowel syndrome and its association with the symptoms observed in patients with irritable bowel syndrome is shown.

GPER activation has been shown to improve macroscopic and microscopic scores as well as reduces the mortality of mice with $\mathrm{CD}$ in relation to untreated mice with $\mathrm{CD}$. In contrast, inhibition of GPER by its selective antagonist G15, was found to be not associated with an improvement of the above mentioned parameters and mortality in the murine model of CD. It is worth noting that GPER is overexpressed in the intestine of male mice with induced CD, as in the intestine of men with $C D$ $(43,44)$. Interestingly, GPER agonists and antagonists affect not only GPER but also nuclear ERs expression and localization. Immunohistochemical analysis revealed that $\mathrm{ER} \alpha$ is localized in the cytoplasm of goblet cells in the intestine of control and TNBS-treated mice supplemented with G-1 and $17 \beta$-estradiol. In contrast, the lack of ER $\alpha$ expression in the cytoplasm of goblet cells has been documented in the intestine of TNBS-treated and TNBS-treated mice supplemented with GPER selective antagonist. Accumulating body of evidence suggests that estrogen signaling is strictly synchronized and all estrogen receptors play a crucial role in the regulation of several major cellular signaling pathways $(20,46-52)$. In the intestine cross-talk between estrogen receptors seems to be important of patients with $C D$ and the value of $E R \alpha / E R \beta$ ratio in the serum may be useful to predict endoscopic activity in CD patients (53). At the molecular level GPER appears to be engaged in the modulation of signaling pathway of extracellular signal-regulated kinases (ERKs), which leads to changes in expression of immune-related genes which was documented in the intestine of IBDs patients and murine model. It was shown that intestine of mice with CD is characterized by higher expression of immunomodulatory genes and GPER activation significantly reduces the levels of immune-related genes (44). The major signaling pathways induced by GPER in bowel diseases are summarized in Figure 3.

\section{COLORECTAL CANCER}

Current evidence based on experimental studies and available datasets provided by Gene Expression Omnibus and Oncomine documented lower expression of GPER at the mRNA and protein levels in the intestine of colorectal cancer (CRC) patients compared to adjacent control tissue (11). Moreover, a gradual decrease of GPER expression appears to be associated with CRC stage and lymph node metastasis in CRC patients (11). Liu et al. (11) provided evidence indicating that promoter methylation and histone $\mathrm{H} 3$ deacetylation represent mechanisms responsible for regulation of GPER expression in CRC. Conflicting results regarding the clinical relevance of GPER expression in CRC patients are from Kaplan-Meier analysis $(11,54,55)$. Lower expression of GPER in the intestine of CRC patients seems to be associated with poorer survival rate in relation to CRC patients with high intestinal expression of GPER (11). On the other hand, Bustos et al. (54) reported that the survival is affected by the sexual dimorphism of CRC patients. Higher expression of GPER has been shown to be associated with poor relapse-free survival in women with stage 3 and 4 but not stage 1 and 2 CRC or men regardless of stage.

The first studies highlighting the role of estrogen signaling through GPER in CRC were conducted by Santolla et al. (56) who found a link between GPER and fatty acid synthase (FASN) in the neoplastic transformation of colon. FASN is a key 
lipogenic enzyme which is able to act as a metabolic oncogene in several types of cancer, such as breast and colorectal cancer (57-59). Functional cross-talk between GPER activation, FASN expression and CRC cells proliferation and migration has been documented. In vitro studies using GPER agonists and LoVo cells have revealed that GPER by affecting the EGFR/ERK/cFos/AP1 signaling pathway is responsible for regulation of FASN expression and modulates the potential for CRC cells proliferation and migration (56). In studies covering a wide spectrum of potential mechanisms that may be involved in CRC progression, Liu et al. (11) found that GPER participates in numerous processes and pathways affecting proliferation of CRC cells. Both in vitro and in vivo studies revealed that GPER is engaged in cell cycle, endoplasmic reticulum stress and modulation of apoptosis which are crucial in the regulation of proliferation, migration and invasion of CRC cells. Liu et al. (11) reported that CRC cells treated with GPER selective agonist G-1 have a higher proportion of cells in the apoptotic phase and their mitochondria are characterized by lower membrane polarity. In line, protein expression analysis showed that treatment of CRC cells with G-1 is related with up-regulation of pro-apoptotic while down-regulation of anti-apoptotic proteins. Activation of reactive oxygen species, ERKs signal and NF-кB suppression appear to be involved in the inhibition of GPER-mediated CRC cell growth. Two-way action of GPER depending on the oxygen level in CRC cells was suggested by Bustos et al. (54). GPER has been shown to be able to modulate two major angiogenic factors, i.e., hypoxia inducible factor (HIF) and vascular endothelial growth factor (VEGF), which are related to the progression of many cancer types. It was found that, under normoxic condition GPER mediates inhibition whereas under hypoxic conditions GPER enhances HIF- $1 \alpha$ and VEGFA expression in CRC cells. Beyond regulation of hypoxia-related genes, estrogens acting through GPER seem to potentiate hypoxia-induced proliferation and migration of CRC cells, while under normoxic condition they suppress cell proliferation and migration of CRC cells (54).

Studies conducted by Gilligan et al. $(55,60)$ clarify the impact of local concentrations of active estrogens and subsequent action on the development and progression of CRC. Clinical observations have indicated that local steroid sulfatase (STS) and 17 $\beta$-hydroxysteroid dehydrogenase (HSD17) B2, B7, and B12 activity and expression in the intestine of CRC patients are disturbed, favoring $17 \beta$-estradiol synthesis in the intestine of CRC patients. STS is an enzyme which converts circulating sulfated estrogen into active form, while HSD17B7 and HSD17B12 catalyze the conversion of estrone to $17 \beta$ estradiol and HSD17B2 catalyzes the conversion of $17 \beta$-estradiol to estrone (61). Both $17 \beta$-estradiol administration and STS overexpression are related with increased CRC cell proliferation, which has been confirmed in in vitro and in vivo models $(55,60)$. Interestingly, estrogens increase proliferation through

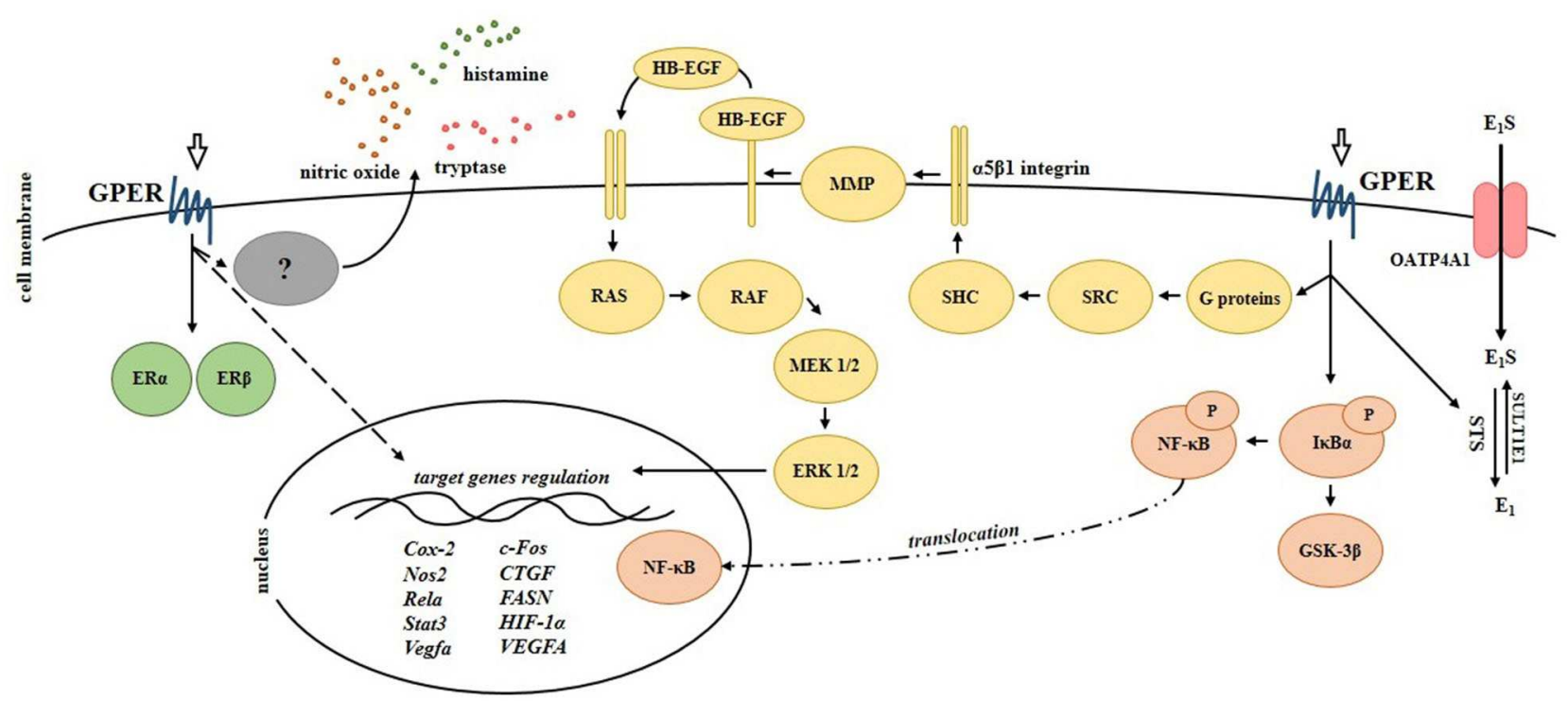

FIGURE 3 | Signaling pathways regulated by G protein-coupled estrogen receptor in the intestinal cells. Scheme shows experimentally proven signals mediated by GPER in bowel diseases. Cox-2, cycloxygenase-2; CTGF, connective tissue growth factor; E1, estrone; $\mathrm{E}_{1} \mathrm{~S}$, estrone sulfate; ER $\alpha$, estrogen receptor $\alpha$; ER $\beta$, estrogen receptor $\beta$; EGFR, epidermal growth factor receptor; ERK 1/2, extracellular signal-regulated kinase 1/2; FASN, fatty acid synthase; c-Fos, FBJ osteosarcoma (subunit

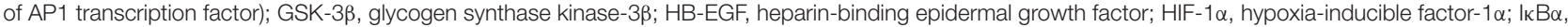
NF-kB inhibitor $\alpha$; MEK 1/2, mitogen-activated protein kinase kinase; MMP, matrix metalloproteinase; NF-кB, nuclear factor $\kappa$-light-chain-enhancer of activated B cells; Nos2, nitric oxide synthase 2; OATP4A1, organic anion transporter polypeptide 4A1; P, phosphorylation; RAF, rapidly accelerated fibrosarcoma (serine-threonine kinase); RAS, rat sarcoma (small GTPase); Rela, nuclear factor NF-кB subunit; SHC, adapter protein containing SRC homology 2 domain; SRC, non-receptor tyrosine kinase; Stat3, signal transducer and activator of transcription 3; STS, steroid sulfatase; SULT1E1, sulfotransferase family 1E member 1; Vegfa/VEGFA, vascular endothelial growth factor $\mathrm{A}$. 


\section{G protein-coupled estrogen receptor regulates:}

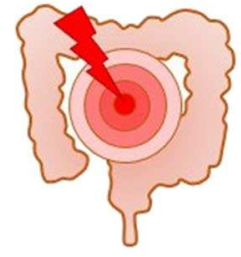

abdominal sensitivity and pain

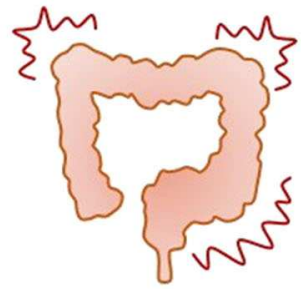

gastrointestinal motility

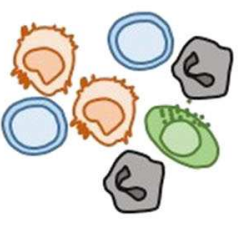

inflammation

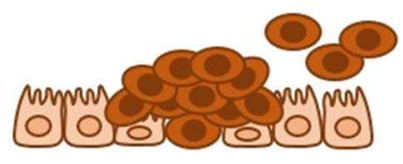

proliferation and migration of colorectal cancer cells

FIGURE 4 | Significance of G protein-coupled estrogen receptor in the intestinal diseases. Scheme illustrating the main symptoms and phenomena regulated by GPER in irritable bowel syndrome, inflammatory bowel diseases and colorectal cancer.

GPER signaling affecting expression of connective tissue growth factor (CTGF), which is crucial factor related to the proliferation, survival, and migration of cancer cells (55). On the other hand, modulation of GPER activity affects STS activity and may act as an estrogenic positive feedback loop leading to the development and progression of CRC (60).

Despite the inconclusive results regarding the level of GPER expression and activity in CRC, the membrane-bound estrogen receptor seems to be an important factor responsible for the modulation of multiple processes leading to the development and progression of CRC. The reasons for these discrepancies may result, for example, from differences in study groups in terms of gender and age. In above mentioned studies, it was proved that the patient's sex seems to be critical in assessing the role of the $G$ protein-coupled estrogen receptor in intestinal diseases. Additionally, the hormonal status of women (pre- and post-menopausal period) is not insignificant and should be taken into consideration in studies on estrogen signaling in intestinal diseases. Different effects of GPER may also be the result of specific cellular context. As demonstrated by Bustos et al. (54) in order to fully understand an estrogenic response it is essential to appreciate not only the estrogen receptor status of the tumor cells but also the hypoxic conditions of the local tumor microenvironment. However, further analysis using clinical material and in vivo models are needed to determine significance of GPER in CRC.

\section{REFERENCES}

1. Owman C, Blay P, Nilsson C, Lolait SJ. Cloning of human cDNA encoding a novel heptahelix receptor expressed in burkitt's lymphoma and widely distributed in brain and peripheral tissues. Biochem Biophys Res Commun. (1996) 228:285-92. doi: 10.1006/bbrc.1996. 1654

2. Carmeci C, Thompson DA, Ring HZ, Francke U, Weigel RJ. Identification of a gene (GPR30) with homology to the G-protein-coupled receptor superfamily associated with estrogen receptor expression in breast cancer. Genomics. (1997) 45:607-17. doi: 10.1006/geno.1997.4972

\section{CONCLUSIONS}

Clinical and experimental studies indicate that nuclear ERs, especially ER $\beta$ which is mainly expressed in the intestine, play an important role in the proliferation and differentiation of intestine cells as well as in the organization and maintenance of intestine architecture. Nevertheless, the available findings support the thesis, that in addition to nuclear ERs, GPER expression and activity is responsible for the development and progression of intestinal diseases, i.e., irritable bowel syndrome, inflammatory bowel diseases and colorectal cancer. GPER has been shown to be involved in abdominal sensitivity and pain, intestinal motility, and colitis as well as proliferation and migration of colorectal cancer cells (Figure 4). However, further studies are needed to determine clinical and therapeutic potential of GPER in bowel diseases.

\section{AUTHOR CONTRIBUTIONS}

DJ and WK contributed to writing, critical revisions, editing and approval of the submitted version of manuscript.

\section{FUNDING}

This work was supported by grants (2017/24/T/NZ5/00045 and $2015 / 17 / \mathrm{N} / \mathrm{NZ} 5 / 00336$ to DJ) from the National Science Center, Poland. 
exposed to fluid shear stress. Biochem Biophys Res Commun. (1997) 240:73741. doi: 10.1006/bbrc.1997.7734

7. Barton M, Filardo EJ, Lolait SJ, Thomas P, Maggiolini M, Prossnitz ER. Twenty years of the G protein-coupled estrogen receptor GPER: historical and personal perspectives. J Steroid Biochem Mol Biol. (2018) 176:415. doi: 10.1016/j.jsbmb.2017.03.021

8. Filardo EJ, Quinn JA, Bland KI, Frackelton, Jr AR. Estrogen-induced activation of Erk-1 and Erk-2 requires the G protein-coupled receptor homolog, GPR30, and occurs via trans-activation of the epidermal growth factor receptor through release of HB-EGF. Mol Endocrinol. (2000) 14:164960. doi: 10.1210/mend.14.10.0532

9. Yang WR, Zhu FW, Zhang JJ, Wang Y, Zhang JH, Lu C, et al. PI3K/Akt activated by GPR30 and Src regulates 17 $\beta$-estradiol-induced cultured immature boar sertoli cells proliferation. Reprod Sci. (2017) 24:5766. doi: $10.1177 / 1933719116649696$

10. Peixoto P, Aires RD, Lemos VS, Bissoli NS, Santos R. GPER agonist dilates mesenteric arteries via PI3K-Akt-eNOS and potassium channels in both sexes. Life Sci. (2017) 183:21-7. doi: 10.1016/j.lfs.2017.06.020

11. Liu Q, Chen Z, Jiang G, Zhou Y, Yang X, Huang H, et al. Epigenetic down regulation of $G$ protein-coupled estrogen receptor (GPER) functions as a tumor suppressor in colorectal cancer. Mol Cancer. (2017) 16:87. doi: 10.1186/s12943-017-0654-3

12. Yu X, Stallone JN, Heaps CL, Han G. The activation of G proteincoupled estrogen receptor induces relaxation via cAMP as well as potentiates contraction via EGFR transactivation in porcine coronary arteries. PloS ONE. (2018) 13:e0191418. doi: 10.1371/journal.pone.0191418

13. Pupo M, Pisano A, Abonante S, Maggiolini M, Musti AM. GPER activates notch signaling in breast cancer cells and cancer-associated fibroblasts (CAFs). Int J Biochem Cell Biol. (2014) 46:56-67. doi: 10.1016/j.biocel.2013.11.011

14. Zhou X, Wang S, Wang Z, Feng X, Liu P, Lv XB, et al. Estrogen regulates hippo signaling via GPER in breast cancer. J Clin Invest. (2015) 125:212335 doi: 10.1172/JCI79573

15. Cheng, S-B, Quinn JA, Graeber CT, Filardo EJ. Down-modulation of the G protein-coupled estrogen receptor, GPER, from the cell surface occurs via a trans-Golgi-proteasome pathway. J Biol Chem. (2011) 286:22441-55. doi: 10.1074/jbc.M111.224071

16. Gonzalez de Valdivia E, Broselid S, Kahn R, Olde B, Leeb-Lundberg LMF. G protein-coupled estrogen receptor 1 (GPER1)/GPR30 increases ERK1/2 activity through PDZ motif-dependent and -independent mechanisms. J Biol Chem. (2017) 292:9932-43. doi: 10.1074/jbc.M116.765875

17. Prossnitz ER, Arterburn JB. International union of basic and clinical pharmacology XCVII G protein-coupled estrogen receptor and its pharmacologic modulators. Pharmacol Rev. (2015) 67:505-40. doi: 10.1124/pr.114.009712

18. Olde B, Leeb-Lundberg LM. GPR30/GPER1: searching for a role in estrogen physiology. Trends Endocrinol Metab. (2009) 20:409-16. doi: 10.1016/j.tem.2009.04.006

19. Prossnitz ER, Barton M. The G-protein-coupled estrogen receptor GPER in health and disease. Nat Rev Endocrinol. (2011) 7:715-26. doi: 10.1038/nrendo.2011.122

20. Jacenik D, Cygankiewicz AI, Krajewska WM. The G protein-coupled estrogen receptor as a modulator of neoplastic transformation. Mol Cell Endocrinol. (2016) 429:10-8. doi: 10.1016/j.mce.2016.04.011

21. Qin B, Dong L, Guo X, Jiang J, He Y, Wang X, et al. Expression of G protein-coupled estrogen receptor in irritable bowel syndrome and its clinical significance. Int J Clin Exp Pathol. (2014) 7:2238-46.

22. Jacenik D, Cygankiewicz AI, Fichna J, Mokrowiecka A, Małecka-Panas E, Krajewska WM. Estrogen signaling deregulation related with local immune response modulation in irritable bowel syndrome. Mol Cell Endocrinol. (2018) 471:89-96. doi: 10.1016/j.mce.2017.07.036

23. Moon TC, Befus AD, Kulka M. Mast cell mediators: their differential release and the secretory pathways involved. Front Immunol. (2014) 5:569. doi: $10.3389 /$ fimmu. 2014.00569

24. Katinios G, Casado-Bedmar M, Walter SA, Vicario M, González-Castro $\mathrm{AM}$, Bednarska $\mathrm{O}$, et al. Increased colonic epithelial permeability and mucosal eosinophilia in ulcerative colitis in remission compared with irritable bowel syndrome and health. Inflamm Bowel Dis. (2020) 16:izz328. doi: 10.1093/ibd/izz328
25. Robles A, Perez Ingles D, Myneedu K, Deoker A, Sarosiek I, Zuckerman MJ, et al. Mast cells are increased in the small intestinal mucosa of patients with irritable bowel syndrome: a systematic review and meta-analysis. Neurogastroenterol Motil. (2019) 31:e13718. doi: 10.1111/nmo.13718

26. Bashashati M, Moossavi S, Cremon C, Barbaro MR, Moraveji S, Talmon G, et al. Colonic immune cells in irritable bowel syndrome: a systematic review and meta-analysis. Neurogastroenterol Motil. (2018) 30:e13192. doi: 10.1111/nmo.13192

27. Sundin J, Nordlander S, Eutamene H, Alquier-Bacquie V, Cartier C Theodorou V, et al. Colonic mast cell numbers, symptom profile, and mucosal expression of elements of the epithelial barrier in irritable bowel syndrome. Neurogastroenterol Motil. (2019) 31:e13701. doi: 10.1111/nmo.13701

28. Zielinska M, Fichna J, Bashashati M, Habibi S, Sibaev A, Timmermans JP, et al. G protein-coupled estrogen receptor and estrogen receptor ligands regulate colonic motility and visceral pain. Neurogastroenterol Motil. (2017) 29:e13025. doi: 10.1111/nmo.13025

29. Xu S, Wang X, Zhao J, Yang S, Dong L, Qin B. GPER-mediated, oestrogendependent visceral hypersensitivity in stressed rats is associated with mast cell tryptase and histamine expression. Fundam Clin Pharmacol. (2020) doi: $10.1111 /$ fcp.12537. [Epub ahead of print].

30. Furness JB. The enteric nervous system: normal functions and enteric neuropathies. Neurogastroenterol Motil. (2008) 20:32-8. doi: 10.1111/j.1365-2982.2008.01094.x

31. Wood JD. Enteric nervous system: neuropathic gastrointestinal motility. Dig Dis Sci. (2016) 61:1803-16. doi: 10.1007/s10620-016-4183-5

32. Li Y, Xu J, Jiang F, Jiang Z, Liu C, Li L, et al. G protein-coupled estrogen receptor is involved in modulating colonic motor function via nitric oxide release in C57BL/6 female mice. Neurogastroenterol Motil. (2016) 28:43242. doi: $10.1111 / \mathrm{nmo} .12743$

33. Liu J, Lin G, Fang M, Rudd JA. Localization of estrogen receptor $\mathrm{ER} \alpha, \mathrm{ER} \beta$ and GPR30 on myenteric neurons of the gastrointestinal tract and their role in motility. Gen Comp Endocrinol. (2019) 272:6375. doi: 10.1016/j.ygcen.2018.11.016

34. Kane SV, Sable K, Hanauer SB. The menstrual cycle and its effect on inflammatory bowel disease and irritable bowel syndrome: a prevalence study. Am J Gastroenterol. (1998) 93:1867-72. doi: 10.1111/j.1572-0241.1998.540_i.x

35. Bharadwaj S, Kulkarni G, Shen B. Menstrual cycle, sex hormones in female inflammatory bowel disease patients with and without surgery. J Dig Dis. (2015) 16:245-55. doi: 10.1111/1751-2980.12247

36. Rolston VS, Boroujerdi L, Long MD, McGovern D, Chen W, Martin CF, et al. The influence of hormonal fluctuation on inflammatory bowel disease symptom severity-a cross-sectional cohort study. Inflamm Bowel Dis. (2018) 24:387-93. doi: 10.1093/ibd/izx004

37. Harnish DC, Albert LM, Leathurby Y, Eckert AM, Ciarletta A, Kasaian M, et al. Beneficial effects of estrogen treatment in the HLA-B27 transgenic rat model of inflammatory bowel disease. Am J Physiol Gastrointest Liver Physiol. (2004) 286:118-25. doi: 10.1152/ajpgi.00024.2003

38. Bábíčková J, Tóthová L, Lengyelová E, Bartonová A, Hodosy J, Gardlík R, et al. Sex differences in experimentally induced colitis in mice: a role for estrogens Inflammation. (2015) 38:1996-2006. doi: 10.1007/s10753-015-0180-7

39. Pierdominici M, Maselli A, Varano B, Barbati C, Cesaro P, Spada C, et al. Linking estrogen receptor $\beta$ expression with inflammatory bowel disease activity. Oncotarget. (2015) 6:40443-51. doi: 10.18632/oncotarget.6217

40. Armstrong CM, Allred KF, Weeks BR, Chapkin RS, Allred CD. Estradiol has differential effects on acute colonic inflammation in the presence and absence of estrogen receptor $\beta$ expression. Dig Dis Sci. (2017) 62:1977-84. doi: 10.1007/s10620-017-4631-x

41. Mohammad I, Starskaia I, Nagy T, Guo J, Yatkin E, Väänänen K, et al. Estrogen receptor a contributes to $\mathrm{T}$ cell-mediated autoimmune inflammation by promoting T cell activation and proliferation. Sci Signal. (2018) 11:eaap9415. doi: 10.1126/scisignal.aap9415

42. Włodarczyk M, Sobolewska-Włodarczyk A, Cygankiewicz AI, Jacenik D, Piechota-Polanczyk A, Stec-Michalska K, et al. G protein-coupled receptor 30 (gpr30) expression pattern in inflammatory bowel disease patients suggests its key role in the inflammatory process. A preliminary study. J Gastrointestin Liver Dis. (2017) 26:29-35. doi: 10.15403/jgld.2014.1121.261.gpr

43. Jacenik D, Cygankiewicz AI, Mokrowiecka A, Małecka-Panas E, Fichna J, Krajewska WM. Sex- and age-related estrogen signaling alteration in 
inflammatory bowel diseases: modulatory role of estrogen receptors. Int J Mol Sci. (2019) 20:3175. doi: 10.3390/ijms20133175

44. Jacenik D, Zielinska M, Mokrowiecka A, Michlewska S, MałeckaPanas E, Kordek R, et al. G protein-coupled estrogen receptor mediates anti-inflammatory action in Crohn's disease. Sci Rep. (2019) 9:6749. doi: 10.1038/s41598-019-43233-3

45. Jacenik D, Zielinska M, Michlewska S, Fichna J, Krajewska WM. Visualization of estrogen receptors in colons of mice with TNBS-induced Crohn's disease using immunofluorescence. J Vis Exp. (2020) 157:e60813. doi: 10.3791/60813

46. Vivacqua A, Bonofiglio D, Recchia AG, Musti AM, Picard D, Andò S, et al. The G protein-coupled receptor GPR30 mediates the proliferative effects induced by $17 \beta$-estradiol and hydroxytamoxifen in endometrial cancer cells. Mol Endocrinol. (2006) 20:631-46. doi: 10.1210/me.2005-0280

47. Albanito L, Madeo A, Lappano R, Vivacqua A, Rago V, Carpino $A$, et al. $G$ protein-coupled receptor 30 (GPR30) mediates gene expression changes and growth response to 17beta-estradiol and selective GPR30 ligand G-1 in ovarian cancer cells. Cancer Res. (2007) 67:1859-66. doi: 10.1158/0008-5472.CAN-06-2909

48. Kang L, Wang ZY. Breast cancer cell growth inhibition by phenethyl isothiocyanate is associated with down-regulation of oestrogen receptor- $\alpha 36$. J Cell Mol Med. (2010) 14:1485-93. doi: 10.1111/j.1582-4934.2009.00877.x

49. Kang L, Zhang X, Xie Y, Tu Y, Wang D, Liu Z, et al. Involvement of estrogen receptor variant ER- $\alpha 36$, not GPR30, in nongenomic estrogen signaling. Mol Endocrinol. (2010) 24:709-21. doi: 10.1210/me.2009-0317

50. Huang GS, Gunter MJ, Arend RC, Li M, Arias-Pulido H, Prossnitz ER, et al. Co-expression of GPR30 and ER $\beta$ and their association with disease progression in uterine carcinosarcoma. Am J Abstetr Gynecol. (2010) 203:242.e1-e5. doi: 10.1016/j.ajog.2010.04.046

51. Gao F, Ma X, Ostmann AB, Das SK. GPR30 activation opposes estrogendependent uterine growth via inhibition of stromal ERK1/2 and estrogen receptor alpha $(\mathrm{ER} \alpha)$ phosphorylation signals. Endocrinology. (2011) 152:1434-47. doi: 10.1210/en.2010-1368

52. Wallacides A, Chesnel A, Ajj H, Chillet M, Flament S, Dumond H. Estrogens promote proliferation of the seminoma-like TCam-2 cell line through a GPER-dependent ER $\alpha 36$ induction. Mol Cell Endocrinol. (2012) 350:6171. doi: 10.1016/j.mce.2011.11.021

53. Linares PM, Algaba A, Urzainqui A, Guijarro-Rojas M, González-Tajuelo $\mathrm{R}$, Garrido J, et al. Ratio of circulating estrogen receptors beta and alpha $(\mathrm{ER} \beta / \mathrm{ER} \alpha)$ indicates endoscopic activity in patients with Crohn's disease Dig Dis Sci. (2017) 62:2744-54. doi: 10.1007/s10620-017-4717-5
54. Bustos V, Nolan ÁM, Nijhuis A, Harvey H, Parker A, Poulsom R, et al. GPER mediates differential effects of estrogen on colon cancer cell proliferation and migration under normoxic and hypoxic conditions. Oncotarget. (2017) 8:84258-75. doi: 10.18632/oncotarget.20653

55. Gilligan LC, Rahman HP, Hewitt AM, Sitch AJ, Gondal A, Arvaniti A, et al. Estrogen activation by steroid sulfatase increases colorectal cancer proliferation via GPER. J Clin Endocrinol Metab. (2017) 102:443547. doi: 10.1210/jc.2016-3716

56. Santolla MF, Lappano R, De Marco P, Pupo M, Vivacqua A, Sisci D, et al. $G$ protein-coupled estrogen receptor mediates the up-regulation of fatty acid synthase induced by $17 \beta$-estradiol in cancer cells and cancer-associated fibroblasts. J Biol Chem. (2012) 287:43234-45. doi: 10.1074/jbc.M112.417303

57. Yoon S, Lee MY, Park SW, Moon JS, Koh YK, Ahn YH, et al. Up-regulation of acetyl-CoA carboxylase alpha and fatty acid synthase by human epidermal growth factor receptor 2 at the translational level in breast cancer cells. J Biol Chem. (2007) 282:26122-31. doi: 10.1074/jbc.M702854200

58. Zhou L, Jiang S, Fu Q, Smith K, Tu K, Li H, et al. FASN, ErbB2-mediated glycolysis is required for breast cancer cell migration. Oncol Rep. (2016) 35:2715-22. doi: 10.3892/or.2016.4627

59. Wang H, Xi Q, Wu G. Fatty acid synthase regulates invasion and metastasis of colorectal cancer via Wnt signaling pathway. Cancer Med. (2016) 5:1599606. doi: 10.1002/cam4.711

60. Gilligan LC, Gondal A, Tang V, Hussain MT, Arvaniti A, Hewitt AM, et al. Estrone sulfate transport and steroid sulfatase activity in colorectal cancer: implications for hormone replacement therapy. Front Pharmacol. (2017) 8:103. doi: $10.3389 /$ fphar.2017.00103

61. RiŽner TL. The important roles of steroid sulfatase and sulfotransferases in gynecological diseases. Front Pharmacol. (2016) 7:30. doi: 10.3389/fphar.2016.00030

Conflict of Interest: The authors declare that the research was conducted in the absence of any commercial or financial relationships that could be construed as a potential conflict of interest.

Copyright (c) 2020 Jacenik and Krajewska. This is an open-access article distributed under the terms of the Creative Commons Attribution License (CC BY). The use, distribution or reproduction in other forums is permitted, provided the original author(s) and the copyright owner(s) are credited and that the original publication in this journal is cited, in accordance with accepted academic practice. No use, distribution or reproduction is permitted which does not comply with these terms. 